INTERSTITIAL LUNG DISEASE

\title{
Radiological versus histological diagnosis in UIP and NSIP: survival implications
}

\author{
K R Flaherty, E L Thwaite, E A Kazerooni, B H Gross, G B Toews, T V Colby, W D Travis, \\ J A Mumford, S Murray, A Flint, J P Lynch III, F J Martinez
}

Thorax 2003;58:143-148

See end of article for authors' affiliations

Correspondence to: Dr F J Martinez, 3916 Taubman Center, $1500 \mathrm{E}$. Medical Center Drive, Ann Arbor, Ml 48109-0360, USA; fmartine@umich.edu

Revised version received 2 October 2002

Accepted for publication

21 October 2002

\begin{abstract}
Background: High resolution computed tomography (HRCT) has an important diagnostic role in idiopathic interstitial pneumonia (IIP). We hypothesised that the HRCT appearance would have an impact on survival in patients with IIP.

Methods: HRCT scans from patients with histological usual interstitial pneumonia (UIP; $n=73$ ) or histological non-specific interstitial pneumonia (NSIP; $n=23$ ) were characterised as definite UIP, probable UIP, indeterminate, probable NSIP, or definite NSIP. Cox regression analysis examined the relationships between histopathological and radiological diagnoses and mortality, controlling for patient age, sex, and smoking status.

Results: All 27 patients with definite or probable UIP on HRCT had histological UIP; 18 of 44 patients with probable or definite NSIP on HRCT had histological NSIP. Patients with HRCT diagnosed definite or probable UIP had a shorter survival than those with indeterminate CT (hazards ratio (HR) 2.43, 95\% $\mathrm{Cl} 1.06$ to 5.58; median survival $2.08 \vee 5.76$ years) or HRCT diagnosed definite or probable NSIP (HR 3.47, $95 \% \mathrm{Cl} 1.58$ to 7.63 ; median survival 2.08 v 5.81 years). Patients with histological UIP with no HRCT diagnosis of probable or definite UIP fared better than patients with histological UIP and an HRCT diagnosis of definite or probable UIP (HR $0.49,95 \% \mathrm{Cl} 0.25$ to 0.98 ; median survival $5.76 \mathrm{v}$ 2.08 years) and worse than those with a histological diagnosis of NSIP (HR $5.42,95 \% \mathrm{Cl} 1.25$ to 23.5; median survival $5.76 v>9$ years).

Conclusions: Patients with a typical HRCT appearance of UIP experience the highest mortality. A surgical lung biopsy is indicated for patients without an HRCT appearance of UIP to differentiate between histological UIP and NSIP.
\end{abstract}

S everal recent studies have shown that examination of surgical lung biopsy specimens allows identification of histopathological subsets of idiopathic interstitial pneumonia (IIP) with different prognoses. ${ }^{1-3}$ High resolution computed tomography (HRCT) has also assumed a greater role in the diagnosis and management of patients with IIP, ${ }^{14-6}$ particularly in distinguishing between usual interstitial pneumonia (UIP) and non-specific interstitial pneumonia (NSIP), the two largest subsets of IIP. UIP has the histopathological pattern also referred to as cryptogenic fibrosing alveolitis and idiopathic pulmonary fibrosis in the UK. Several groups have highlighted the imaging findings and diagnostic accuracy of HRCT scanning for patients with UIP. ${ }^{4-9}$ The ability of HRCT to distinguish UIP and NSIP is more controversial, with recent reports suggesting a varying radiological picture in NSIP. ${ }^{810} 11$ This study examines whether HRCT features add prognostic information to the histological classification in the differential diagnosis of UIP and NSIP, and determines whether the current radiological criteria for NSIP are useful in histologically proven cases of NSIP. We hypothesised that differences in survival would exist between patients with well defined histological UIP and NSIP on the basis of the CT appearance.

\section{METHODS}

\section{Patient selection}

Patients from the University of Michigan Specialized Center of Research (SCOR) in the Pathobiology of Fibrotic Lung Disease database were consecutively referred by participants in the University of Michigan Fibrotic Lung Disease Network (see Appendix) and underwent surgical lung biopsy between October 1989 and February 2000. Members of this network refer patients to the SCOR in the Pathobiology of Fibrotic Lung
Disease when IIP is suspected based on criteria defined by consensus guidelines. ${ }^{6}{ }^{12}$ Surgical lung biopsy was performed either by open thoracotomy or video assisted thoracoscopy. Surgeons were asked to obtain multiple biopsy specimens and were able to achieve this in $76 / 96$ patients $(79 \%)$. Included in the current report are patients with a histological diagnosis of UIP or NSIP (by surgical lung biopsy) and an HRCT scan within 6 months of the biopsy. Patients with an associated collagen vascular illness were excluded. The treatments were started after surgical lung biopsy and are shown in table 1 .

\section{Physiological testing}

Pulmonary function tests including spirometry, lung volumes, and transfer factor for carbon monoxide (TLCO) were performed before surgical lung biopsy as previously described. ${ }^{13}$

\begin{tabular}{|c|c|c|}
\hline Treatment regimen & $\begin{array}{l}\text { UIP } \\
(n=73)\end{array}$ & $\begin{array}{l}\text { NSIP } \\
(n=23)\end{array}$ \\
\hline None & $5 \quad(7 \%)$ & $1(4 \%)$ \\
\hline Prednisone alone & $19(26 \%)$ & $11(48 \%)$ \\
\hline Prednisone + azathioprine or cyclophosphamide & 25 (34\%) & $4(18 \%)$ \\
\hline Zileuton* & $17(23 \%)$ & $3(13 \%)$ \\
\hline Azathioprine alone & $5(7 \%)$ & $3(13 \%)$ \\
\hline Miscellaneous & $2(3 \%)$ & $1(4 \%)$ \\
\hline
\end{tabular}

UIP = usual interstitial pneumonia; NSIP = non-specific interstitial pneumonia.

*These patients were treated as part of a phase I trial comparing zileuton with azathioprine conducted at our institution. 


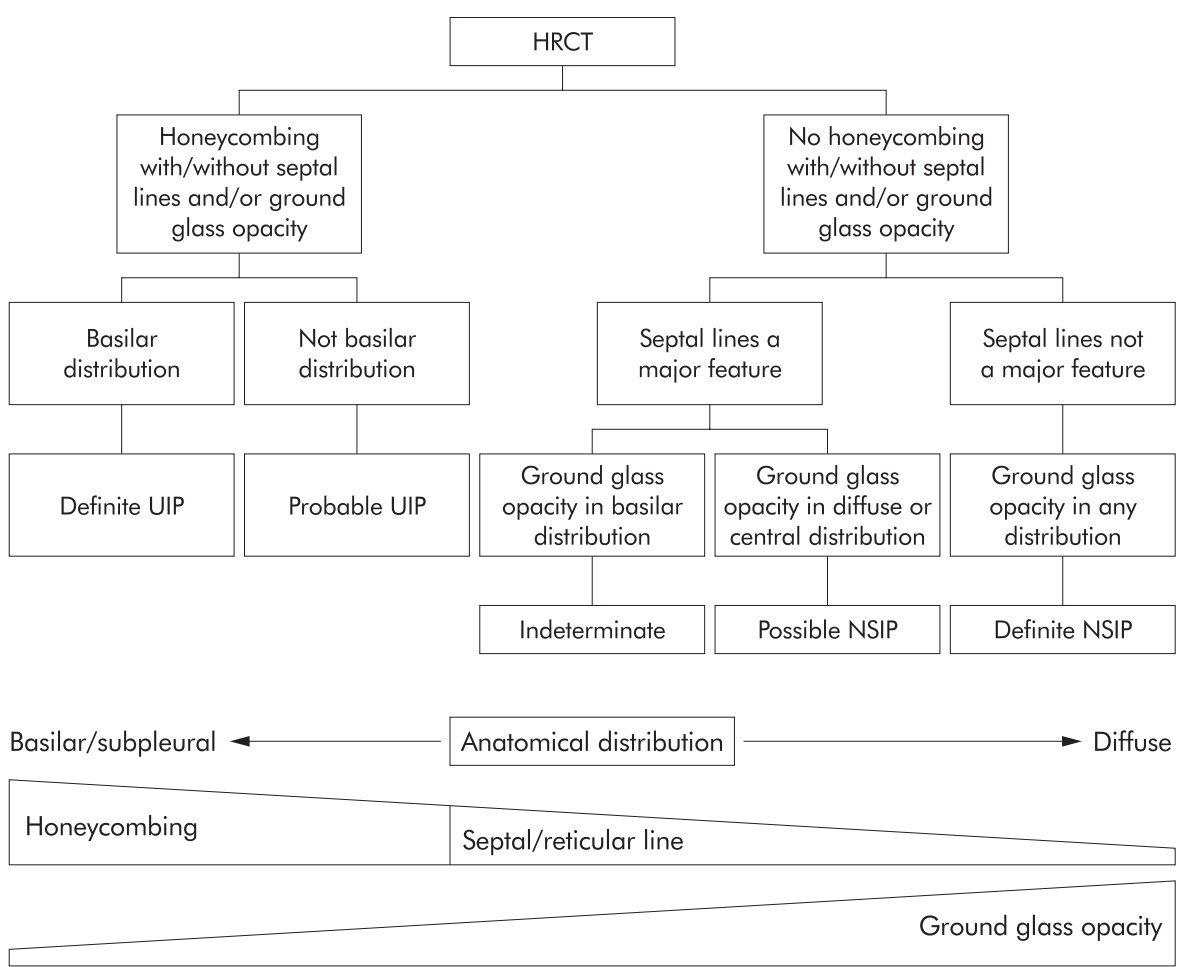

Figure 1 Diagnostic algorithm used to classify the HRCT pattern as definite UIP, probable UIP, indeterminate (equal probability of UIP or NSIP), probable NSIP, or definite NSIP. The algorithm reflects a theoretical continuum of distribution, degree of reticular/honeycomb change, and degree of ground glass opacity illustrated below the algorithm. Generally, patients with a more basilar/subpleural distribution, more reticular infiltrates, and less ground glass were felt to have UIP. Patients with a more diffuse distribution, less reticular infiltrates, and more ground glass were felt to have NSIP.

High resolution computed tomography (HRCT)

HRCT was performed with 1.0 or $1.5 \mathrm{~mm}$ thick sections taken at $1 \mathrm{~cm}$ intervals throughout the entire lung during inspiration in the supine position and through the caudal $10 \mathrm{~cm}$ of the lung at $2 \mathrm{~cm}$ increments in the prone position. ${ }^{14}$ Images were reconstructed using a high spatial frequency reconstruction algorithm. Two thoracic radiologists (EAK, BHG) independently reviewed each HRCT scan and recorded each case as either definite UIP, probable UIP, indeterminate (equal probability of UIP or NSIP), probable NSIP, or definite NSIP. The criteria used included those widely accepted as most consistent with these diagnoses. ${ }^{915}{ }^{16}$ These criteria are illustrated in fig $\mathrm{l}$. The finding felt by the radiologists to indicate probable or definite UIP was honeycombing, as this finding correlates strongly with pathological fibrosis and impaired survival. ${ }^{1317}$ The absence of honeycombing, the presence of ground glass opacity, and an apical or non-subpleural distribution favoured NSIP. ${ }^{1118}$ Radiologists were not asked to

\begin{tabular}{|c|c|c|c|c|c|}
\hline & \multicolumn{2}{|c|}{ Histological UIP } & \multirow[b]{2}{*}{$\begin{array}{l}\text { Histological } \\
\text { NSIP (3) }\end{array}$} & \multirow[b]{2}{*}{$\begin{array}{l}\text { p value } \\
(1)=(2)=(3)\end{array}$} & \multirow[b]{2}{*}{$\begin{array}{l}\text { p value } \\
(1)=(2)\end{array}$} \\
\hline & $\begin{array}{l}\text { HRCT UIP } \\
\text { (1) }\end{array}$ & $\begin{array}{l}\text { HRCT not UIP } \\
(2)\end{array}$ & & & \\
\hline $\operatorname{Sex}(F / M)$ & $8 / 19$ & $26 / 20$ & $13 / 10$ & 0.060 & 0.03 \\
\hline Age (years) & $64(8)$ & $60(12)$ & 54 (11) & $0.004^{*}$ & 0.06 \\
\hline Onset (years) & $3.6(2.6)$ & $2.2(2.6)$ & $2.5(3.7)$ & 0.12 & 0.03 \\
\hline Weight (kg) & 84 (16) & 86 (19) & $88(18)$ & 0.70 & 0.67 \\
\hline Non-smokers (\%) & $19.2(39.4)$ & 46.5 (49.9) & $39.1(48.8)$ & 0.07 & 0.03 \\
\hline Pack years & $18(17)$ & $19(26)$ & $24(28)$ & 0.69 & 0.86 \\
\hline FVC (I) & $2.95(1.0)$ & $2.36(0.8)$ & $2.6(0.8)$ & 0.18 & 0.11 \\
\hline FVC (\% pred) & $76(21)$ & $64(19)$ & 70 (17) & 0.18 & 0.12 \\
\hline $\mathrm{FEV}_{1}$ (I) & $2.32(0.8)$ & $1.93(0.7)$ & $1.98(0.6)$ & 0.29 & 0.18 \\
\hline FEV $1 \%$ pred) & $85(23)$ & $72(21)$ & 72 (17) & 0.21 & 0.15 \\
\hline TLC (I) & $4.56(1.1)$ & $4.05(1.4)$ & $4.57(1.9)$ & 0.33 & 0.25 \\
\hline TLC (\% pred) & $79(15)$ & $73(19)$ & $84(18)$ & 0.17 & 0.33 \\
\hline TLCO & $10.31(5.7)$ & $14.47(5.5)$ & $13.61(3.11)$ & 0.08 & 0.07 \\
\hline TLCO (\% pred) & $40(20)$ & $56(16)$ & $57(14)$ & $0.03^{*}$ & 0.05 \\
\hline \multicolumn{6}{|c|}{$\begin{array}{l}\text { Values are mean (SD). } \\
\text { UIP=usual interstitial pneumonia; NSIP=non-specific interstitial pneumonia; onset=duration of symptoms } \\
\text { before surgical lung biopsy; FVC=forced vital capacity; FEV } 1 \text { =forced expiratory volume in } 1 \text { second; } \\
\text { TLC=total lung capacity; TicO=carbon monoxide transfer factor. } \\
\text { *Additional comparisons with NSIP that were significant at the } p<0.05 \text { level in post hoc analysis were: age } \\
\text { (1) } \vee(3) \text {, (2) } \vee(3) ;(1) \text { and (2) } \vee(3) ; \text { TLCO (\% pred) (1) } \vee(3) \text {. }\end{array}$} \\
\hline
\end{tabular}


Table 3 HRCT consensus diagnosis segregated by final histological diagnosis

\begin{tabular}{lccl}
\hline \multirow{2}{*}{$\begin{array}{l}\text { Consensus } \\
\text { HRCT diagnosis }\end{array}$} & \multicolumn{3}{l}{ Histological diagnosis } \\
\cline { 2 - 4 } & UIP & NSIP & Total \\
\hline Definite UIP & 16 & 0 & 16 \\
Probable UIP & 11 & 0 & 11 \\
Indeterminate & 20 & 5 & 25 \\
Probable NSIP & 17 & 8 & 25 \\
Definite NSIP & 9 & 10 & 19 \\
Total & 73 & 23 & 96 \\
\hline
\end{tabular}

$\mathrm{HRCT}=$ high resolution computed tomography; UIP=usual interstitial pneumonia; NSIP=non-specific interstitial pneumonia.

differentiate between cellular and fibrotic NSIP. In those cases where initial disagreement was present, a consensus opinion was obtained by re-review of the cases by both radiologists as a consensus panel.

\section{Pathological classification}

Three pathologists (TVC, WDT, AF) blinded to the clinical and radiological features reviewed the biopsy specimens. Each specimen was assigned a histological diagnosis of UIP or NSIP using defined criteria. ${ }^{319}$ A patient received a diagnosis of UIP when one or more biopsy specimens showed UIP. ${ }^{20}$ Cases of cellular NSIP $(n=3)$ and fibrotic NSIP $(n=20)$ were collectively classified as NSIP.

\section{Statistical analysis}

Comparisons between baseline characteristics for continuous measurements were carried out using ANOVA (three group comparisons) and two sample $t$ tests (two group comparisons) allowing for unequal variances. Associations between categorical variables were evaluated using Pearson's $\chi^{2}$ statistics $^{21}$ or Fisher's exact test. ${ }^{22}$ Interobserver agreement of the radiological diagnoses was described using kappa and weighted kappa statistics, where weighted kappa statistics confer partial agreement for assignment of adjacent diagnoses-for example, definite and probable UIP, or probable UIP and indeterminate assignments. ${ }^{23}$ Interobserver agreement between radiologists was first evaluated across all five diagnostic categories (definite UIP, probable UIP, indeterminate, probable NSIP, and definite NSIP). It was also evaluated between radiologists for three grouped diagnostic categories (definite or probable UIP, indeterminate, and probable or definite NSIP). This later analysis was performed as the survival experience for probable versus definite UIP and probable versus definite NSIP were similar. Survival experiences with patients segregated by histological and radiological diagnoses were compared using the log rank test ${ }^{24}$ and displayed using Kaplan-Meier curves. ${ }^{25}$. Analyses presented include all cause mortality as of August 2001. Cox regression analysis was used to examine the relationship between histopathological or radiological diagnosis and mortality, controlling for other potential confounders including patient age, sex, and smoking status. ${ }^{26}$

\section{RESULTS}

\section{Patients}

The cohort included 73 patients with histological UIP and 23 with histological NSIP. Compared with the 27 patients with histological UIP and a definite or probable HRCT diagnosis of UIP, the 46 with histological UIP without a definite or probable HRCT diagnosis of UIP were more likely to be women $(p=0.03)$, to have a shorter duration of symptoms $(p=0.03)$, to be younger $(p=0.06)$, to be non-smokers $(p=0.03)$, and to have a higher TLCo \% predicted $(p=0.05)$. Patients with histological NSIP were younger than patients with histological UIP
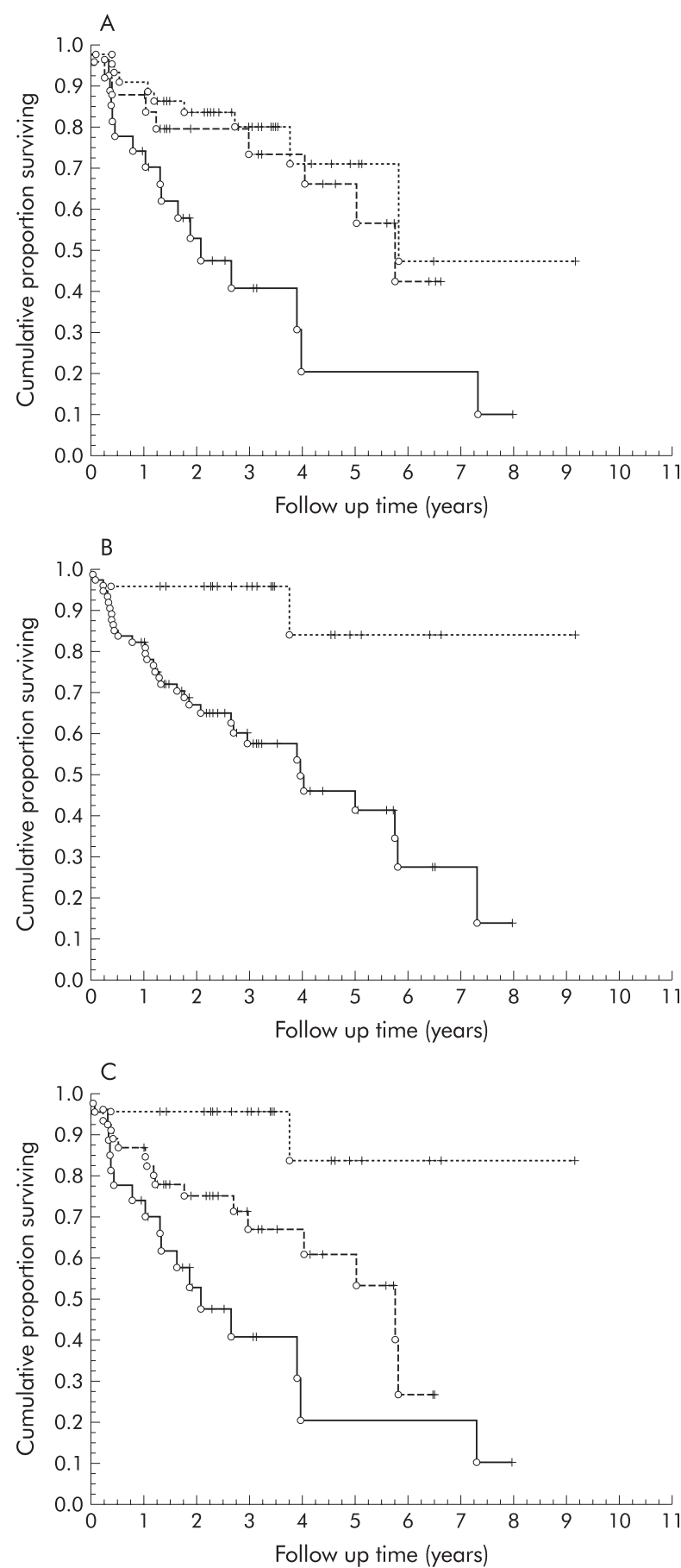

Figure 2 Kaplan-Meier survival curves for $(A)$ patients with an HRCT diagnosis of NSIP ( $n=44$, dotted line), indeterminate $(n=25$, dashed line), and UIP ( $n=27$, solid line), $p=0.01$; (B) patients with a histopathological diagnosis of NSIP ( $n=23$, dotted line) and UIP $(n=73$, solid line), $p=0.0006$; and $(C)$ patients grouped by combining HRCT and histopathological features as follows: histopathological pattern showing NSIP and HRCT was interpreted as indeterminate or NSIP ( $n=23$, dotted line), histopathological pattern showing UIP and HRCT was interpreted as indeterminate or NSIP ( $n=46$, dashed line), and histopathological pattern showing UIP and HRCT was interpreted as UIP ( $n=27$, solid line), $p=0.001 .+=$ last follow up visit; $\mathrm{O}=$ death.

(independent of HRCT results, $\mathrm{p}<0.05$ ) and had a higher TLCO $\%$ predicted $(\mathrm{p}<0.05)$ than patients with histological UIP and an HRCT diagnosis of UIP (table 2). Most of the patients with either UIP $(n=58,79 \%)$ or NSIP $(n=15,78 \%)$ had a biopsy 
Table 4 Median survival by diagnostic category

\begin{tabular}{|c|c|c|c|}
\hline Diagnostic category & $\begin{array}{l}\text { Median }(95 \% \mathrm{Cl}) \\
\text { survival (years) }\end{array}$ & $\begin{array}{l}\text { No }(\%) \text { of } \\
\text { patients }\end{array}$ & $\begin{array}{l}\text { Deaths } \\
\text { (n) }\end{array}$ \\
\hline \multicolumn{4}{|l|}{ Histological diagnoses } \\
\hline Histological UIP & $3.98(2.71$ to 5.81$)$ & $73(76)$ & 34 \\
\hline Histological NSIP & $>9$ years (NA) & $23(24)$ & 2 \\
\hline \multicolumn{4}{|l|}{ HRCT diagnoses } \\
\hline HRCT definite/probable UIP & $2.08(1.30$ to 3.98$)$ & $27(28)$ & 17 \\
\hline HRCT indeterminate & $5.76(4.03$ to $\mathrm{NA})$ & $25(26)$ & 9 \\
\hline HRCT definite/probable NSIP & 5.81 (5.81 to NA) & $44(46)$ & 10 \\
\hline \multicolumn{4}{|l|}{ Histological pattern and HRCT diagnoses } \\
\hline Histological UIP and HRCT definite/probable UIP & $2.08(1.30$ to 3.98$)$ & $27(28)$ & 17 \\
\hline $\begin{array}{l}\text { Histological UIP and HRCT indeterminate or } \\
\text { definite/probable NSIP }\end{array}$ & $5.76(4.03$ to $N A)$ & $46(48)$ & 17 \\
\hline Histological NSIP and HRCT definite/probable NSIP & $>9$ years (NA) & 18 (19) & 2 \\
\hline Histological NSIP and HRCT indeterminate & $>6.6$ years $(\mathrm{NA})$ & $5(5)$ & 0 \\
\hline
\end{tabular}

specimen taken from more than one lobe (Fisher's exact for association between diagnosis and biopsy in more than one lobe, $\mathrm{p}=1.0$ ).

\section{HRCT diagnoses}

The radiologists had complete agreement in 35 (36\%) of the cases $(\mathrm{kappa}=0.20, \mathrm{p}<0.000 \mathrm{l}$; weighted $\mathrm{kappa}=0.43$, $\mathrm{p}<0.0001$ ). When probable or definite UIP were combined and probable or definite NSIP were combined, agreement improved to $61(64 \%)$ of the cases (kappa $=0.43, \mathrm{p}<0.0001$; weighted $k a p p a=0.52, p<0.0001)$. A consensus diagnosis was reached for all the remaining cases that lacked initial independent agreement. In 25 cases the consensus shift was to radiologist 1 , in 27 cases the consensus shift was to radiologist 2, and in nine cases the final consensus diagnosis was between either radiologist's initial interpretation. Twenty seven patients had a radiological picture which was felt to represent definite or probable UIP; in all of these patients a histological diagnosis of UIP was confirmed (table 3). All 27 were among the 73 patients with histological UIP (37\% of UIP cases). In contrast, only 18 of 44 patients with HRCT features suggestive of probable or definite NSIP had histological NSIP. As such, the radiologists demonstrated a high specificity (100\%) but a low sensitivity (37 (SD 6)\%) in identifying UIP and a sensitivity of 78 (SD 9)\% and specificity of 64 (SD 6)\% for identifying NSIP.

Fifty eight patients with histological UIP had a biopsy specimen taken from at least two lobes. UIP was present in all lobes in 39 patients (67\%) and a combination of UIP and NSIP was found between lobes in 19 patients (33\%). Patients with histological UIP in all lobes were more likely to have an HRCT appearance of definite or probable UIP (15/39, 38\%) than patients with a combination of histological UIP and NSIP between lobes $(3 / 19,16 \%$, Fisher's exact test, $p=0.05)$.

\section{Survival}

Patients with a histological diagnosis of UIP had worse survival (32 deaths/73 patients) than those with a histological diagnosis of NSIP (2 deaths/23 patients) (hazard ratio $(\mathrm{HR})=7.24,95 \%$ CI 1.74 to $30.2, \log$ rank $\mathrm{p}=0.0015)$. The median follow up was 3.1 years (95\% CI 2.3 to 4.4 ) and 3.3 years (95\% CI 3.0 to 4.9 ) for histological UIP and histological NSIP, respectively. There was no difference in survival when patients with HRCT diagnoses of definite UIP versus probable UIP $(\mathrm{HR}=1.67,95 \%$ CI 0.60 to $4.64, \log$ rank $\mathrm{p}=0.32)$, or when patients with HRCT diagnoses of definite versus probable NSIP $(\mathrm{HR}=1.31,95 \%$ CI 0.38 to $4.54, \log$ rank $\mathrm{p}=0.67)$ were compared. We therefore grouped patients with a definite or probable HRCT diagnosis of UIP as HRCT UIP and those with a definite or probable HRCT diagnosis of NSIP as HRCT NSIP for the remainder of the survival analyses.
The combination of biopsy and HRCT findings allowed for the most discrete separation of patients into groups with different prognoses (fig 2A-C). Patients with an HRCT diagnosis of UIP had the worst survival profile with a higher risk of death than those with an indeterminate HRCT diagnosis $(\mathrm{HR}=2.45,95 \%$ CI 1.06 to $5.67, \log$ rank $\mathrm{p}=0.03)$ and those with an HRCT diagnosis of NSIP (HR=3.5, 95\% CI 1.59 to 7.71 , $\log$ rank $\mathrm{p}=0.001$ ). Importantly, patients with both an HRCT and histological diagnosis of UIP fared worse than those with a histological diagnosis of UIP in the absence of an HRCT diagnosis of UIP (HR=2.03, 95\% CI 1.02 to 4.05, log rank $\mathrm{p}=0.04$; fig 2C). Patients with histological UIP and an HRCT diagnosis of indeterminate or NSIP had a higher risk of death than those with histological NSIP ( $\mathrm{HR}=5.29,95 \%$ CI 1.22 to 23.0, $\log$ rank $\mathrm{p}=0.01$; fig 2C). Median survival estimates by diagnostic category are shown in table 4. Survival profiles across treatment groups were not significantly different (log rank $\mathrm{p}=0.40$ ). Treatment regimens by histopathological diagnosis were not significantly different (Fisher's exact test, $\mathrm{p}=0.22$ ).

In multivariate analyses, statistically insignificant protective effects were seen for younger patients, smokers, and women. Effect sizes maintained similar magnitude and directions to the unadjusted analysis and also remained statistically significant or marginally significant. The HR for a patient with both histological and HRCT UIP compared with a patient with histological NSIP was 11.40 (95\% CI 2.38 to 54.59 , $\mathrm{p}=0.002$ ). The HR of a patient with histological UIP in the absence of HRCT UIP compared with a patient with histological NSIP was 5.58 (95\% CI 1.25 to $24.85, p=0.024)$. The HR of a patient with both histological and HRCT UIP diagnosis compared with histological UIP in the absence of a typical HRCT pattern of UIP was 2.04 (95\% CI 0.88 to $4.73, p=0.095$ ). Each of these comparisons was adjusted for age, smoking status, and sex. Similar results were observed when the physiological status was included and when the three patients with cellular NSIP were excluded (data not shown). When treatment categories were added to the multivariate models the parameter estimates did not converge, so reliable conclusions regarding the effect of treatment could not be determined.

\section{DISCUSSION}

In this study of patients with histologically well defined UIP and NSIP we found that: (1) patients with an HRCT pattern of UIP are likely to have a histopathological pattern of UIP, but patients with an HRCT pattern other than UIP may have either a histological pattern of UIP or NSIP on the surgical lung biopsy specimen; (2) HRCT features add prognostic information to the histological diagnosis of UIP; survival was worse if patients with histological UIP had an HRCT picture felt by 
expert radiologists to be definite or probable UIP compared with patients with histological UIP but an atypical HRCT picture for UIP; and (3) HRCT has limited specificity in identifying histological NSIP.

We have quantified the median survival of patients with a histological diagnosis of UIP and typical HRCT findings. These patients have a significantly worse prognosis (median survival 2.08 years) than patients with histological UIP but atypical HRCT findings (median survival 5.76 years). Controversy exists regarding survival in patients with UIP diagnosed using biopsy or HRCT criteria. Survival in patients with UIP by clinical and HRCT criteria have been reported to be $\operatorname{similar}^{17}{ }^{27}$ and worse $^{28}$ than those diagnosed by surgical lung biopsy. Our findings are strengthened by the large number of patients and by the application of the latest histological criteria for diagnosing UIP or NSIP by three pathologists independently. ${ }^{19}$ In addition, the radiological criteria were applied by two expert radiologists independently who ultimately achieved consensus diagnoses of UIP or NSIP. Our data are of particular significance because they document the potential survival bias depending on the method used to diagnose UIP. If the HRCT criteria we describe (and not lung biopsy) are used to diagnose UIP, later stage UIP appears to be preferentially selected. We urge stratification according to both HRCT and biopsy findings in future studies of UIP.

Our findings suggest that HRCT criteria identify patients with later stage UIP. Patients with UIP and a typical HRCT appearance of UIP had a longer duration of symptoms, decreased gas transfer, and tended to be older. Accordingly, the worse survival noted for patients with histological UIP and a typical HRCT appearance of UIP is probably related to disease severity. This concept is supported by data suggesting that honeycombing develops and becomes more widespread during serial follow up in patients with UIP. ${ }^{29-32}$

This study was designed to assess differences in survival based on HRCT appearance in an established cohort. In addition, the radiologists placed particular weight on the presence of subpleural basal predominant honeycomb changes as being strongly supportive of an HRCT diagnosis of probable or definite UIP. These features have been shown to be particularly important in predicting survival when examined in a semiquantitative fashion. ${ }^{1314}$ Importantly, these typical HRCT features of UIP were seen in only a few of the patients with a histological diagnosis of UIP $(27 / 73,37 \%)$. This sensitivity is lower than in some reports ${ }^{933}$ but similar to more recent data. ${ }^{11}$ The differences may relate to the stringent radiological criteria used to diagnose UIP in the current study and the presence of an indeterminate radiological category. The interobserver agreement in our study was good and similar to that reported by experienced observers in previous studies. ${ }^{11634}$ It is important to emphasise that radiologists with differing levels of experience and expertise can interpret radiographic images differently. ${ }^{35}$ The radiologists in this study are specialists in thoracic radiology and have extensive expertise in the interpretation of HRCT scans from patients with suspected IIP. The level of agreement and interpretations could differ if this study was repeated using general radiologists who may have a more general knowledge of a broader range of material. Furthermore, agreement between radiologists may differ if they use different diagnostic criteria or algorithms for the classification of UIP and NSIP. Further studies are needed to evaluate radiographic diagnostic criteria and the specificity, predictive ability, and level of agreement for patients evaluated by less experienced radiologists.

Our study provides strong support for the concept that no currently identified single feature or combination of HRCT features has high specificity for a histological diagnosis of NSIP. ${ }^{36}$ HRCT findings of ground glass opacity and reticular abnormality were not accurate predictors of histological NSIP. In our series most of the patients with typical HRCT findings of NSIP had a histological diagnosis of UIP at surgical lung biopsy $(26 / 44,59 \%)$. In addition, patients with histological UIP who lacked the typical features of UIP on HRCT scanning experienced a worse survival than those with histological features of NSIP. Furthermore, $26 \%$ of cases (25/96) were categorised as indeterminate (having an equal probability of UIP or NSIP) by two radiologists evaluating HRCT scans using the radiological criteria shown in fig 1 .

Although some studies have suggested predominant ground glass ${ }^{11}$ and parenchymal consolidation ${ }^{37}$ with a subpleural predominance in $\mathrm{NSIP}^{38}$ others have expanded the spectrum of radiological abnormalities seen in NSIP. ${ }^{10} 3940$ Importantly, one multicentre group found HRCT findings consistent with UIP in 15 of 50 patients with biopsy proven NSIP. ${ }^{10}$ However, in our study all patients with HRCT findings consistent with UIP had a histological pattern of UIP. These differences may reflect sampling error inherent in surgical lung biopsy, evolution in histological criteria, or differential criteria used by radiologists. Our data support a diagnostic approach to IIP that incorporates histological and radiological findings as advocated by expert groups, ${ }^{6}$ and indicate that surgical lung biopsy should be considered for patients with an HRCT picture which suggests NSIP.

In summary, we have shown that an HRCT diagnosis of UIP can reliably predict a histological pattern of UIP, although the converse does not apply as many patients with histological UIP lack stereotypical HRCT features. In those patients without the stereotypical HRCT features of UIP, there is a significant difference in survival between those found to have histological NSIP and those with histological UIP. Surgical lung biopsy is therefore required in these patients to provide accurate prognostic information. Furthermore, among patients with a histological diagnosis of UIP, there is a difference in survival between those with HRCT features suggestive of UIP and those without these HRCT features. Our data provide further clarification as to which patients will benefit from surgical lung biopsy and give important information for stratification of patients in studies where survival is an outcome variable.

\section{APPENDIX}

The University of Michigan Fibrotic Lung Disease Network includes: University of Michigan, Division of Pulmonary and Critical Care, Ann Arbor, MI (D Arenberg, C Brennan-Martinez, W Bria, D Dahlgren, S Gay, C Grum, J Hampton, K Hariharan, M Keane, T Ojo, M Peters-Golden, R Simon, T Sisson, T Standiford, R Strieter); Internal Medicine Clinic, Alpena, MI (P Bachwich, C Easton, J Mazur); The Lung Center, Battle Creek, MI (S Chaparala, G Harrington, N Potempa); Bay City, MI (S Manawar, J Summer); Clawson, MI (P Hukku, J Sung); Clinton Township, MI (R Babcock); Pulmonary and Critical Care Medicine Consultants, Commerce, MI (J Belen, M Dunn, D Maxwell, R Reagle, R Sherman, S Simecek); Oakwood Hospital, Dearborn, MI (L Victor); Henry Ford Hospital, Detroit, MI (B DiGiovine, M Eichenhorn, R Hyzy, J Popovich Jr, D Spizarny); Botsford General Hospital, Farmington Hills, MI (B Rabinowitz); Pulmonary and Critical Care Specialists, Farmington Hills, MI (G Ferguson, P Kaplan, S Sklar, W VanderRoest); Pulmonary Associates, PC, Flint, MI (O Filos, V Rao, MV Thomas, J Varghese, J Vyskocil, F Wadenstorer); Grand Valley Internal Medicine, Grand Rapids, MI (J Cantor, W Katz, R Johnson, Jr., D Listello, J Wilt); Michigan Medical Professional Company, Grand Rapids, MI (C Acharya, W Couwenhoven, T Daum, M Harrison, M Koets, G Sandman, G VanOtteren); Michigan Medical, PC, Holland, MI (S Kraker); Huntington Woods, MI (M Greenberger, A O'Neill, D Wu); Pulmonary Clinics of Southern Michigan, Jackson, MI (RC Albertson III, J Chauncey, T Murray, G Patten); Associated Pulmonary and Critical Care Specialists, PC, Kalamazoo, MI (T Abraham, J Dirks, B Dykstra, G Grambau, J Schoell); Pulmonary and Critical Care Associates, PC, Kalamazoo, MI (R Brush, S Jefferson, J Miller, S Schuldheisz, M Warlick); Pulmonary and Critical Care Consultants, Lansing, MI ( $\mathrm{J}$ Armstrong, A Atkinson, T Kantra, L Rawsthorne, D Young); Pulmonary Services, Lansing, MI (A Abbasi, CM Gera, G Kashyap, J Morlock); Respiratory Medicine, Marquette, MI (S Danek, A Saari); Midland, MI (S Yadam); Central Michigan Healthcare System, Mt Pleasant, MI (E Obeid); Muskegon Pulmonary Associates, 
Muskegon, MI (D Hoch, A Kleaveland); Owosso Medical Group, Owosso, MI (A Allam, MA Gad Jr); Lung Associates, Pontiac, MI (A Desai, U Dhanjal, A Sethi); St Joseph's Hospital, Pontiac, MI (F Ahmad, R Elkus, L Kaiser, L Rosenthal, D Sak); Physician HealthCare Network, Port Huron, MI (R Ailani, M Basha, A Hadar, S Holstine): Pulmonary, Critical Care, and Sleep, PC, Rochester Hills, MI (MW Al-Ameri, R Go, M Kashlan); Rochester, MI (K Aggarwal); Roseville, MI (W Hanna, R Marchese); William Beaumont Hospital, Royal Oak, MI (R Begle, D Erb, KP Ravikrishnan, J Seidman, S Sherman); Saginaw, MI (R Agarwal, F, Ansari, T Damuth, C Indira); Spring Lake, MI (M Ivey); Lakeside Healthcare Specialists, St Joseph, MI (S Deskins, A Palmer, S Shastri); Pulmonary and Critical Care Associates, St Clair Shores, MI and Troy, MI (R DiLisio, S Galens, K Grady, D Harrington, R Herbert, C Hughes, J Lee, A Starrico, K Stevens, M Trunsky, W Ventimiglia); Taylor, MI (D Mahajan); Pulmonary Medicine Associates, Warren, MI (H Kaplan, L Tankanow); Henry Ford Wyandotte Hospital, Wyandotte, MI (M Pensler); Toledo Pulmonary and Sleep Specialists, Toledo, OH (FO Horton III, A Nathanson, R Wainz).

\section{Authors' affiliations}

K R Flaherty, G B Toews, J P Lynch III, F J Martinez, Division of Pulmonary and Critical Care Medicine, University of Michigan Health System, Ann Arbor, MI, USA

E L Thwaite, E A Kazerooni, B H Gross, Department of Radiology, University of Michigan Health System

A Flint, Department of Pathology, University of Michigan Health System, W D Travis, Armed Forces Institute of Pathology

T V Colby, Mayo Clinic, Scottsdale, AZ, USA

J A Mumford, S Murray, Department of Biostatistics, University of Michigan School of Public Health

Supported in part by National Institutes of Health NHLBI Grant \#P5OHL46487, NIH/NCRR 3 MOI RR00042-33S3, NIH/NIA P60 AG08808-06, NHLBI, 1 K24 HL04212, and 1 K23 HL68713.

\section{REFERENCES}

1 American Thoracic Society. Idiopathic pulmonary fibrosis: diagnosis and treatment. International consensus statement. Am J Respir Crit Care Med 2000;161:646-64.

2 Ryu JH, Colby TV, Hartman TE. Idiopathic pulmonary fibrosis: current concepts. Mayo Clin Proc 1998;73:1085-101.

3 Katzenstein ALA, Myers JL. Idiopathic pulmonary fibrosis. Clinical relevance of pathologic classification. Am J Respir Crit Care Med 1998; 157:1301-15.

4 Hunninghake GW, Zimmerman MB, Schwartz DA, et al. Utility of a lung biopsy for the diagnosis of idiopathic pulmonary fibrosis. Am J Respir Crit Care Med 2001;164:193-6.

5 Raghu G. Interstitial lung disease: a diagnostic approach. Are CT scan and lung biopsy indicated for every patient? Am J Respir Crit Care Med 1995; 151:909-14.

6 American Thoracic Society/European Respiratory Society. American Thoracic Society/European Respiratory Society international multidisciplinary consensus classification of the idiopathic interstitial pneumonias. Am J Respir Crit Care Med 2002;165:277-304.

7 Tung KT, Wells AU, Rubens MB, et al. Accuracy of the typical computed tomographic appearances of fibrosing alveolitis. Thorax 1993;48:334-8

8 Johkoh T, Muller NL, Cartier Y, et al. Idiopathic interstitial pneumonias: diagnostic accuracy of thin-section CT in 129 patients. Radiology 1999:211:555-60.

9 Raghu G, Mageto YN, Lockhart D, et al. The accuracy of the clinical diagnosis of new-onset idiopathic pulmonary fibrosis and other interstitia lung disease: a prospective study. Chest 1999;116:1168-74.

10 Hartman TE, Swensen SJ, Hansell DM, et al. Nonspecific interstitial pneumonia: Variable appearance at high-resolution chest CT. Radiology 2000;217:701-5.

11 MacDonald SLS, Rubens MB, Hansell DM, et al. Nonspecific interstitial pneumonia and usual interstitial pneumonia: comparative appearances at and diagnostic accuracy of thin-section CT. Radiology 2001;221:600-5.

12 British Thoracic Society. The diagnosis, assessment and treatment of diffuse parenchymal lung disease in adults. Thorax 1999;54(Suppl 1):S1-30.
13 Gay SE, Kazerooni EA, Toews GB, et al. Idiopathic pulmonary fibrosis. Predicting response to therapy and survival. Am J Respir Crit Care Med 1998;157:1063-72

14 Kazerooni EA, Martinez FJ, Flint A, et al. Thin-section CT obtained at 10-mm increments versus limited three-level thin-section CT for idiopathic pulmonary fibrosis: correlation with pathologic scoring. AJR 1997:169:977-83.

15 Nishimura K, Kitaichi M, Izumi T, et al. Usual interstitial pneumonia: histologic correlation with high-resolution CT. Radiology 1992; 182:337-42.

16 Collins CD, Wells AU, Hansell DM, et al. Observer variation in pattern type and extent of disease in fibrosing alveolitis on thin section computed tomography and chest radiography. Clin Radiol 1994;49:236-40.

17 Mogulkoc N, Brutsche MH, Bishop PW, et al. Pulmonary function in idiopathic pulmonary fibrosis and referral for lung transplantation. Am J Respir Crit Care Med 2001;164:103-8.

18 Kim EY, Lee KS, Chung MP, et al. Nonspecific interstitial pneumonia with fibrosis: serial high-resolution CT findings with functional correlation. AJR 1999; 173: 1734-9.

19 Travis WD, Matsui K, Moss J, et al. Idiopathic nonspecific intersititial pneumonia: prognostic signficance of cellular and fibrosing patterns. Am J Surg Pathol 2000;24:19-33.

20 Flaherty KR, Travis WD, Colby TV, et al. histologic variability in usua and nonspecific interstitial pneumonias. Am J Respir Crit Care Med $2001 ; 164: 1722-7$

21 Pearson K. On the criterion that a given system of deviations from the probable in the case of a correlated system of variables is such that it can be resonably supposed to have arisen from random sampling. Philosophical Magazine 1900; Series 5, 50:157-75.

22 Fisher RA. The logic of inductive inference. J R Stat Soc 1935;98A: 39-54

23 Cohen J. Weighted kappa: nominal scale agreement with provision for scaled disagreeement or partial credit. Psychol Bull 1968;70:213-20.

24 Mantel N. Evaluation of survival data and tow new rank-order statistics arising in its consideration. Cancer Chemothe Rep 1966;50

25 Kaplan EL, Meier P. Nonparametric estimation from incomplete observations. J Am Stat Assoc 1958;53:457-81.

26 Cox DR. Regression models and life tables (with discussion). J R Stat Soc 1972;B34: 187-220.

27 Douglas WW, Ryu JH, Swensen SJ, et al. Colchicine versus prednisone in the treatment of idiopathic pulmonary fibrosis. A randomized prospective study. Am J Respir Crit Care Med 1998;158:220-5.

28 Daniil ZD, Gilchrist FC, Nicholson AG, et al. A histologic pattern of nonspecific interstitial pneumonia is associated with a better prognosis than usual interstitial pneumonia in patients with cryptogenic fibrosing alveolitis. Am J Respir Crit Care Med 1999;160:899-905.

29 Lee JS, Gong G, Song KS, et al. Usual interstitial pneumonia: relationship between disease activity and the progression of honeycombing at thin-section computed tomography. J Thorac Imaging 1998; 13:199-203.

30 Akira M., Sakatani M., Ueda E. Idiopathic pulmonary fibrosis: progression of honeycombing at thin-section CT. Radiology 1993; 189:687-91

31 Akira M, Yamamoto S, Hara $\mathrm{H}$, et al. Serial computed tomographic evaluation in desquamative interstitial pneumonia. Thorax 1997;52:333-7.

32 Wells AU, Rubens MB, DuBois RM, et al. Serial CT in fibrosing alveolitis: prognostic significance of the initial pattern. AJR 1993;161:1 159-65.

33 Wells A. Clinical usefulness of high resolution computed tomography in cryptogenic fibrosing alveolitis. Thorax 1998:53:1080-7.

34 Wells AU, Rubens MB, du Bois RM, et al. Serial CT in fibrosing alveolitis: prognostic significance of the initial pattern. AJR 1993;161:1 159-65.

35 Eng J, Mysko WK, Weller GE, et al. Interpretation of emergency department radiographs: a comparison of emergency medicine physicians with radiologists, residents with faculty, and film with digital display. AJR 2000;175:1233-8

36 Reynolds JH, Hansell DM. The interstitial pneumonias: understanding the acronyms. Clin Radiol 2000;55:249-60.

37 Park JS, Lee KS, Kim JS, et al. Nonspecific interstitial pneumonia with fibrosis: radiographic and CT findings in seven patients. Radiology 1995; 195:645-8.

$38 \mathrm{Kim}$ TS, Lee KS, Chung MP, et al. Nonspecific interstitial pneumonia with fibrosis: High-resolution CT and Pathologic findings. AVR 1998;171:1645-50.

39 Nagai S, Kitaichi $M$, Itoh $\mathrm{H}$, et al. Idiopathic nonspecific interstitial pneumonia/fibrosis: comparison with idiopathic pulmonary fibrosis and BOOP. Eur Respir J 1998;12:1010-9.

40 Cottin V, Donsbeck A-V, Revel D, et al. Nonspecific interstitial pneumonia: individualization of a clinicopathologic entity in a series of 12 patients. Am J Respir Crit Care Med 1998;158:1286-93. 